\title{
DOIS LADOS DA MESMA MOEDA: O TEMPO NO STF
}

\author{
Carlos Henrique Borlido Haddad e Lucas Bacelette Otto Quaresma
}

\section{RESUMO}

O artigo situa-se no Direito Processual Penal e consiste EM PESQUISA EMPÍRICA COM OBJETIVO DE IDENTIFICAR OS CRITÉRIOS UTILIZADOS PELO STF PARA DISTINGUIR O EXCESSO DE PRAZO NA FORMAC̣ÃO DA CULPA DA RAZOÁVEL DURAÇÃO DO PROCESSO. EXAMINARAM-SE 229 ACÓRDÃOS PROFERIDOS EM JULGAMENTOS DE HABEAS CORPUS NOS ANOS DE 1991/1992, 2001/2002 E 2011/2012 E FORAM SELECIONADOS AQUELES EM QUE ERA POSSÍVEL IDENTIFICAR A DURAÇÃO DA PRISÃO PROVISÓRIA. FOI NOTADO AUMENTO DO PRAZO DA PRISÃO PROVISÓRIA AO LONGO DOS ANOS, MAS SE CONSTATOU QUE O TEMPO NÃO É O PRINCIPAL FATOR PARA SEPARAR PRAZO RAZOÁVEL DO EXCESSO DE PRAZO. A GRAVIDADE DA INFRAÇÃO E A COMPLEXIDADE DO PROCESSO PESAM COMO CRITÉRIOS PREPONDERANTES. O STF NÃO ADOTA LIMITES TEMPORAIS PRECISOS PARA RECONHECER O EXCESSO DE PRAZO E A ANÁLISE MOSTRA-SE CASUÍSTICA A PONTO DE PROCESSOS MAIS LONGOS SEREM CLASSIFICADOS COMO DE DURAÇÃO RAZOÁVEL.

\section{PALAVRAS-CHAVE}

PROCESSO PENAL; STF; PRISÃO; PRAZO RAZOÁVEL; EXCESSO DE PRAZO.

\begin{abstract}
THE PAPER DEALS WITH THE FIELD OF CRIMINAL PROCEDURE AND REPORTS EMPIRICAL RESEARCH WHOSE GOAL WAS TO IDENTIFY THE CRITERIA USED BY THE STF TO DISTINGUISH UNDUE DELAY VS. REASONABLE TIME IN CRIMINAL CASES. A TOTAL OF 229 HABEAS CORPUS DECISIONS WERE ANALYZED WHICH HAD BEEN RULED ON DURING THE PERIODS 1991-1992, 2001-2002 AND 2011-2012. CASES IN WHICH IT WAS POSSIBLE TO DETERMINE THE LENGTH OF THE DETENTION TIMES WERE SELECTED FOR ANALYSIS. AN INCREASE OF TIME SPENT IN JAIL OVER THE YEARS WAS NOTICED, BUT IT WAS FOUND THAT TIME WAS NOT THE MAIN FACTOR IN DISTINGUISHING UNDUE DELAY OR REASONABLE DURATION. THE COMPLEXITY OF THE CASES AND THE GRAVITY OF THE CRIMES WERE PREPONDERANT FACTORS. THE STF DOESN'T ADOPT SPECIFIC LIMITS TO RECOGNIZE UNDUE DELAY AND THE DECISIONS WERE MADE IN A CASUISTIC WAY. THEREFORE, SOME CASES WITHOUT A DECISION FOR MANY YEARS WERE CLASSIFIED AS CASES DECIDED WITHIN A REASONABLE TIME.
\end{abstract}

\section{KEYWORDS}

CRIMINAL PROCEDURE; STF; DETENTION; REASONABLE TIME; UNDUE DELAY.

\section{INTRODUÇÃO}

7 anos, 4 meses e 17 dias não é pouco tempo.

O período é superior à duração de todos os mandatos eletivos brasileiros, à exceção do de Senador. O plano de metas de Juscelino Kubitscheck - 50 anos em 5 também era mais curto e nesse lapso temporal consegue-se graduar nos mais variados cursos superiores, do Direito à Medicina. Corresponde a pouco mais do que a décima 
parte da expectativa de vida do brasileiro, mas sob o olhar do STF foi tachado de razoável. Ao julgar o Habeas Corpus n. 109.349, ${ }^{1}$ em que se sustentava excesso de prazo na formação da culpa, o tribunal denegou a ordem e expressou que o trâmite processual se dava de maneira razoável, a despeito de o acusado permanecer preso por 7 anos, 4 meses e 17 dias sem julgamento em primeira instância.

As peculiaridades do caso penal analisado talvez expliquem o teor da decisão, mas também fazem surgir a questão em torno do que se conceitua como razoável duração no âmbito processual penal. Como avaliar se a duração do processo, em que o acusado aguarda o julgamento preso, mostrou-se excessiva ou dentro de parâmetros aceitáveis?

Para responder essa pergunta e procurar critérios que diferenciam o excesso de prazo na formação da culpa do prazo razoável, realizou-se pesquisa na jurisprudência do STF com específicos cortes temporais. Escolheram-se as decisões do STF como objeto de investigação porque o tribunal, por ocupar o último posto na hierarquia de instâncias judiciais, examina questões atinentes a processos criminais que contam com maior duração temporal. Foram analisados acórdãos de habeas corpus julgados em 1991/1992, 2001/2002 e 2011/2012, com o objetivo de verificar a evolução da percepção do tribunal sobre a aludida diferenciação. O procedimento de coleta de dados foi feito pela ferramenta de pesquisa on-line de jurisprudência do site do STF (www.stf.jus.br) e se utilizaram como parâmetros os termos "excesso prazo penal", que abrangiam o tema central investigado, seja para refutar ou confirmar sua ocorrência. Como critério de inclusão, selecionaram-se os bancos de dados de acórdãos e repercussões gerais, o que significa que súmulas e decisões monocráticas foram excluídas da pesquisa.

A amostra total está representada por 229 acórdãos, os quais foram lançados em planilhas do Microsoft Excel e classificados de acordo com as seguintes informações: (1) número do processo; (2) nome do relator; (3) termo inicial e final da prisão; (4) tipificação penal; (5) se houve ou não deferimento de liminar; (6) teor do parecer do Ministério Público; (7) número de réus; (8) resultado do julgamento; e (9) argumentação. A principal variável está representada pelo item 3 , relacionada ao tempo de duração da prisão processual. Elaboraram-se três planilhas para cada série temporal, a fim de medir as variáveis a intervalos de tempo (BRACARENSE, 2005, p. 33): uma contendo os acórdãos em que a ordem foi concedida, outra com aqueles em que houve denegação e a terceira contendo os números de todos os acórdãos identificados, mas que foram excluídos da composição da pesquisa. Programou-se a planilha para fornecer o exato tempo de permanência na prisão, medido em dias, por meio da elaboração de células que calculavam a duração do encarceramento com base nas datas iniciais e finais extraídas dos julgados. Identificada a duração da prisão em cada processo, escolheu-se como medida de tendência central apenas a média aritmética, calculada pela soma dos valores individuais, dividida pelo número total de processos. 
A mediana e a moda, embora pudessem demonstrar a distribuição (as)simétrica da variável principal da pesquisa, não foram adotadas em razão da possibilidade de o pequeno conjunto de dados nos primeiros cortes temporais gerar associações aleatórias não detectadas em conjuntos maiores. Além disso, foi reconhecido que a média aritmética possui as melhores propriedades de um estimador (BRACARENSE, 2005, p. 48).

Os critérios de exclusão do procedimento amostral ativeram-se aos acórdãos que não tratavam de habeas corpus, mas de outras ações ou recursos; que não foram conhecidos no que tange à alegação de excesso de prazo, por motivos variados (supressão de instância, aplicação das súmulas 21 e 52 do STJ etc.); aqueles em que, com base nas informações constantes do inteiro teor do acórdão, não se pôde aferir o tempo de prisão do paciente; e ainda os processos em que o paciente não se encontrava preso.

O tamanho final da amostra consolidou-se em 85 acórdãos, que foram efetivamente analisados para aferir o posicionamento do STF acerca dos dois lados da mesma moeda: excesso de prazo na formação da culpa e prazo razoável.

\section{i Tempo e Processo}

Qual é a medida do tempo?

A resposta à questão pode não ser tão singela.

Notoriamente, o tempo é medido pelo movimento dos astros no céu ou pelos ritmos biológicos do corpo humano, a que se liga a ideia de um tempo exterior e homogêneo, no qual nos encontramos imersos e do qual só nos restaria fragmentar o desenvolvimento em períodos fixos. Também pode ser apreendido pelo ângulo da percepção mais imediata, mais subjetiva, em que seria aferido de acordo com a vivência de uma experiência individual (OST, 2005, p. 19-20). A par do tempo como fenômeno físico ou como experiência psíquica, Ost percebe o tempo como produto de construção social, a que denomina temporalização, com poder de sedimentar concepções, valores e culturas. Esse aspecto cultural do tempo torna-se claro quando se observa a existência de diversas formas de contar o tempo (calendários), conforme a história de cada povo, cada qual com seu momento fundador distinto.

Para o autor, a sociedade avança a diversas velocidades e não faz mais do que duas décadas que testemunhamos substancial incremento na velocidade com que as coisas são feitas. O aperfeiçoamento dos sistemas de informática provocou percebida mudança na forma como as pessoas realizam transações financeiras, que vão desde o acesso a contas bancárias via internet, passando pela aquisição on-line de produtos até a transferência internacional de recursos. A distribuição de músicas e filmes sofreu profunda alteração. Informações estão disponíveis imediatamente sem origem física precisa. As comunicações globais tornaram-se instantâneas e realizadas por áudio e vídeo. Aparelhos portáteis substituíram dezenas de instrumentos e fazem às vezes de telefone, 
agenda, rádio, câmera fotográfica e televisão em único e reduzido corpo. A instantaneidade e a imediatidade da vida moderna reduziram a dimensão da paciência e transformaram a espera em algo indesejado. Na economia globalizada, o sentido de tempo é dado por racionalidade de caráter material, pelo cálculo de custo/benefício e pelas expectativas de lucro com relação a um dado ciclo de rotação dos capitais (FARIA, 1997, p. 306).

No entanto, as mudanças experimentadas pelos processos judiciais possuem caráter apenas marginal. Nos tribunais, o tempo é associado ao garantismo processual, forjado como instrumento de organização social e controle da dinâmica dos processos judiciais. A legislação processual penal continua sendo basicamente regida pelo tempo diferido, isto é, por etapas que se articulam de maneira sucessiva, por fases que se sucedem cronologicamente. A tramitação prevista nas leis de processo e enraizada nas rotinas e cultura judiciária é uma tramitação que tem o seu lastro na cultura do papel, assente em despachos judiciais extensamente fundamentados, em sentenças de várias páginas, que repetem a base instrutória, os fundamentos das partes, extensa doutrina; e em articulados e requerimentos das partes bastante longos, com cansativa repetições de fatos e de argumentação jurídica (SANTOS, 2008, p. 131). Conquanto todos os tribunais mantenham informações disponíveis em ambientes virtuais e alguns já tenham substituído papel por monitor, o processo judicial permanece praticamente o mesmo. O Código de Processo Civil remonta a 1973 e o Código de Processo Penal foi elaborado na década de 1940, com pequena maquilagem no último lustro. Não há dúvida de que a população do século passado possuía outras expectativas de tempo, percepções de eficiência e sentidos de vida. Não seria surpresa que hoje nutrissem esperança em ver resolvido o processo judicial em escasso período de tempo, a reforçar a desconexão entre o ritmo da vida na economia globalizada e o andamento do sistema judicial brasileiro.

Nenhuma das outras responsabilidades na administração de tribunais, tais como a gestão de pessoal, o gerenciamento financeiro e o arquivamento de documentos, é tão direta e estritamente relacionada ao objetivo básico do Poder Judiciário do que a redução do atraso no andamento dos processos (STEELMAN, 2008, p. 1). No âmbito penal, a perpetuação do processo além do tempo necessário para assegurar os direitos fundamentais do acusado converte-se na principal violação de todas e de cada uma das diversas garantias que o réu possui (BADARÓ, LOPES JR., 2006, p. 8). Se o processo penal é instrumento de efetivação das garantias constitucionais, no qual se assegura ao acusado mecanismos de proteção contra atos arbitrários por parte do Estado, observa-se que a tutela não se faz completa se a tramitação processual se estende por tempo desarrazoado. Afirmar que a instauração do processo criminal é a certeza que o indivíduo tem de que seus direitos serão respeitados (RANGEL, 2012, p. 505) somente seria exatamente verdadeiro se, no curso da ação penal, não houvesse lentidão excessiva na constatação da culpabilidade. 
É universal a tendência das legislações em acelerar o processo, seja estabelecendo limites temporais normativos para a conclusão do julgamento, seja prescrevendo regras que estimulem a obtenção de celeridade. A Constituição Federal de 1988 dispõe que "a todos, no âmbito judicial e administrativo, são assegurados a razoável duração do processo e os meios que garantam a celeridade de sua tramitação" (art. 5\%, LXXVIII). O dispositivo, com similar previsão no art. 111 da Constituição italiana, que assegura a ragionevole durata, não se fez acompanhar por regulamentação ordinária correspondente. Ao contrário do país peninsular, onde se editou a Legge Pinto (Lei n. 89, de 24 de março de 2001) para tentar solucionar as muitas demandas em que figurava como réu no Tribunal Europeu de Direito Humanos (TEDH), não há norma específica no Brasil que vise a tornar efetiva a disposição constitucional. Segundo Rangel (2012, p. 44), trata-se de norma programática, que não possui instrumentalidade efetiva. Se não há divergências na doutrina sobre o enquadramento do direito ao prazo razoável, que significa o direito a uma justiça tempestiva, o direito ao processo sem dilações indevidas (BADARÓ, LOPES JR, 2006, p. 17), o conceito não é objetivamente fornecido pela lei brasileira e necessita ser construído pelos tribunais.

O Tribunal Europeu de Direitos Humanos (TEDH) trilhou esse caminho ao identificar a mora judicial nas diversas ações que tramitaram nos sistemas judiciários de variados Estados e contribuiu para disseminar parâmetros para definição da razoável duração do processo. A corte possui experiência muito grande a respeito do julgamento de demandas indenizatórias, propostas por cidadãos europeus contra os respectivos países, por atrasos do sistema judicial. Para oTEDH, a noção de dilação processual indevida remete a conceito indeterminado, cujo conteúdo é obtido mediante a aplicação de critérios objetivos às circunstâncias específicas de cada caso (KOEHLER, 2013, p. 91). Os critérios empregados pelo tribunal são: (1) a complexidade do processo; (2) o comportamento da parte lesada; (3) o comportamento das autoridades envolvidas no processo; (4) e o interesse em jogo para o demandante da indenização.

Os principais fundamentos de uma célere tramitação do processo criminal, sem atropelo de garantias fundamentais, estão calcados no respeito à dignidade do acusado, no interesse probatório, no interesse coletivo no correto funcionamento das instituições e na própria confiança na capacidade da justiça de resolver os assuntos que a ela são levados (BADARÓ, LOPES JR., p. 14, 2006). Os interesses em jogo são relevantes, mas, a despeito disso, não há medida certa para determinar o prazo razoável do processo criminal. A duração prolongada da prisão processual é análoga à perenidade da memória punitiva de que fala Ost (2005, p. 100), em que castigar significa, antes de tudo, recordar. No entanto, não é papel do processo penal castigar o acusado e a indeterminação da prisão cautelar apenas indicia que o processo penal brasileiro peca em ser instrumento para veicular garantias.

Por meio da presente pesquisa, pretende-se apurar quais critérios são adotados pelo STF para identificar a mora do sistema judiciário criminal. Tenciona-se verificar 
se existem limites temporais objetivos, estabelecidos pelo tribunal, para a finalização dos processos criminais ou se, a exemplo do TEDH, são utilizados critérios maleáveis para identificar no caso concreto quando o prazo de duração se avulta intolerável.

\section{Resultados Quantitativos}

A busca no repositório de jurisprudência identificou 165 acórdãos no período mais recente, que compreende o biênio 2011/2012. Do total, apenas 60 interessam ao objeto do trabalho. Destes, em 27 a ordem foi denegada e, em 33, concedida. Os demais que constaram dos resultados na plataforma de pesquisa de jurisprudência do site do STF foram descartados pelas razões expostas anteriormente. No período 2001 / 2002, o mesmo parâmetro de busca detectou 44 acórdãos, dos quais apenas 18 apresentaram relevância para a pesquisa. Em 14 habeas corpus a ordem foi denegada e em 4 ações, concedida. Por fim, no lapso bienal de 1991/1992, localizaram-se 20 acórdãos, embora apenas 7 interessassem à pesquisa, com 3 concessões e 4 denegações da ordem.

\section{I TIPO DE CRIME}

As infrações penais pelas quais os pacientes foram processados e que motivaram a alegação de excesso de prazo no STF são basicamente duas: tráfico ilícito de drogas e homicídio qualificado. Peculato, roubo, extorsão mediante sequestro e lavagem de dinheiro também figuram no rol de crimes, mas as infrações previstas no art. 33 da Lei n. 11.343/06 e no art. 121, § 2 , do Código Penal, com ou sem associação criminosa em ambos os casos, despontam em 69\% dos habeas corpus em que foi possível identificar a capitulação jurídica constante da denúncia.

\subsection{NúMERO DE RÉUS}

Nos 85 processos pesquisados nos três biênios, a multiplicidade de réus constitui a regra. Apenas em 6 ações (menos de 10\%), havia um único réu no processo que tramitava nas instâncias inferiores. A quantidade de agentes varia consideravelmente e o HC 69.172 / RJ, por exemplo, referia-se a processo em que foram denunciados 190 acusados. O número de 4 agentes, limite mínimo para configuração da quadrilha ou bando, anteriormente à Lei n. 12.850/13, foi o mais recorrente, apesar de não muito expressivo.

\subsection{Relator}

Houve grande diversidade em torno da atuação dos relatores nos processos em que se discutia o excesso de prazo na formação da culpa. Mas é interessante notar que, nos casos de concessão da ordem, a Ministra Cármen Lúcia e o Ministro Marco Aurélio foram relatores, respectivamente, em 9 e 8 dos 33 acórdãos analisados no 
biênio 2011/2012. Nos casos de denegação, os Ministros Ricardo Lewandowski e Gilmar Mendes relataram 6 e 5 dos 27 acórdãos, respectivamente.

\subsection{LIMINAR}

É atribuição do relator do habeas corpus, em havendo fundamentos que o justifiquem, conceder medidas liminares. Nos 85 processos analisados, foram concedidas 12 medidas liminares, 10 das quais em feitos em que, ao final, ela foi confirmada. Em 2 processos, houve concessão da liminar, mas a ordem foi denegada posteriormente.

\subsection{Parecer do Ministério Público}

O regimento interno do STF (art. 192, § $2^{\circ}$ ) prevê a manifestação do Procurador-Geral da República nos processos de habeas corpus. Nos casos em que houve denegação da ordem, existe robusta identidade entre o teor do parecer e o resultado do julgamento. Dos 45 habeas corpus denegados apenas em 5 houve divergência, com parecer favorável à concessão. Por outro lado, a dissonância amplia-se nos 40 processos em que a ordem foi concedida, porque houve parecer contrário do Procurador-Geral em 23 feitos, o que corresponde a 57,5\% dos casos.

\subsection{Prazo de Formação da CULPa}

Os dados mais importantes visados e que puderam ser apurados são os referentes à duração do processo criminal, cujo (suposto) excesso deu causa ao ajuizamento das ações de habeas corpus. Os resultados foram bem distintos em cada corte temporal com intervalo decenal. No biênio 2011/2012, a diferença da média de tempo em que a ordem foi concedida ou denegada em razão do excesso de prazo foi pouco expressiva. Nos processos em que a ordem foi denegada, a prisão provisória estendeu-se por 1229,40 dias em média; nos casos de deferimento, o prazo médio da prisão processual era de 1245,06 dias.

Os valores próximos da década de 2010 não foram notados no período 2001 / 2002. Nesta época, houve reconhecimento do excesso de prazo quando a prisão provisória durava 1056,25 dias, mas a ordem foi negada quando o prazo equivalia à média de 750,50 dias.

Por fim, as médias de tempo aferidas foram, pela primeira vez, invertidas: 748,50 dias para os habeas corpus em que se denegou a ordem e 435,67 dias de tempo médio de prisão que configurou excesso de prazo na formação da culpa, durante o biênio $1991 / 1992$.

O prazo mais curto de sujeição à prisão processual que caracterizou excesso de prazo foi delineado no HC 82.506/SP, relatora Ministra Ellen Gracie, com duração de 142 dias. Em segundo lugar, posta-se o HC 69.172/RJ, de relatoria do Ministro Marco Aurélio. Neste caso, a ordem foi concedida porque a ré já havia obtido decisão concessiva de liberdade provisória, posteriormente cassada pelo Tribunal de Justiça com 
fundamento apenas nas acusações que lhe eram feitas. O prazo da custódia provisória foi de 238 dias. No outro extremo, além do HC 109.349/MG, de relatoria do Ministro Gilmar Mendes, mencionado no início do trabalho e que computava 2692 dias de prisão processual, pode ser citado o HC 98.620/RJ, relatado pelo Ministro Marco Aurélio, em que, a despeito dos 2371 dias de custódia preventiva, a ordem foi denegada.

\section{Resultados Qualitativos}

A análise qualitativa considera os critérios empregados pelo STF para aferição do excesso de prazo na formação da culpa nos processos de réus presos. Procurou-se descrever os principais argumentos empregados pelo tribunal para conceder ou denegar a ordem de habeas corpus.

Durante o biênio 2011/2012, no qual há maior número de processos, em quase $100 \%$ dos casos em que se denegou a ordem, a expressão "complexidade do caso" foi mencionada no corpo do acórdão. Por seu turno, a definição de "complexidade" não é muito clara, mas é possível perceber que os processos em que há mais de um réu classificam-se, quase sempre, como complexos. Não existe definição precisa sobre qual seria o número mínimo de acusados para que o processo fosse considerado complexo e parece bastar a existência de mais de um agente.

Nos 33 habeas corpus em que o pedido foi deferido, 14 o foram apenas para que a autoridade coatora (normalmente Ministro Relator de habeas corpus no STJ) julgasse o feito que tramitava perante o tribunal superior por extenso lapso temporal. Nesses casos, a fundamentação do voto do ministro relator asseverava que se tratava de "situação excepcional”, pois, normalmente, não caberia ao STF influir na pauta de julgamento de outros tribunais.

Nos biênios anteriores, a fundamentação para denegação da ordem é bem similar àquela adotada pelo STF nos julgamentos analisados no período de 2011/2012, principalmente a referência à "complexidade do processo" e o fato de a demora resultar de “comportamento da defesa”. Quanto a este último aspecto, é digna de nota a referência a dois acórdãos que denegaram a ordem. No HC 80.855/RJ, de relatoria da Ministra Ellen Gracie, a ordem foi denegada no tocante à alegação de excesso de prazo, sob fundamento de que o retardamento se devia ao comportamento da defesa que "insistia na oitiva do mesmo número de testemunhas que o MP". Entretanto, ao final, a ordem foi parcialmente concedida, não para relaxar a prisão do paciente, mas tão somente para garantir que a defesa pudesse arrolar a mesma quantidade de testemunhas indicadas pela acusação. Por seu turno, o HC 80.188/RJ tinha como relator o Ministro Marco Aurélio, que foi vencido, e trata de caso bastante peculiar: o impetrante alega excesso de prazo na formação de culpa em favor de paciente que aguardava julgamento em sede de protesto por novo júri. Os debates travados entre os ministros giraram em torno da questão da formação da culpa em caso de protesto 
por novo júri, se a admissão do referido recurso conferiria ao réu o status anterior à condenação. Apenas o Ministro Marco Aurélio entendeu que prevaleceria a presunção de inocência, mas seus pares defenderam a tese de que, em caso de protesto por novo júri, não retornaria o réu à situação anterior à condenação. Cuidava de ato criminoso que envolveu extrema violência e gerou muita repercussão, conhecido como "Chacina de Vigário Geral”, no qual houve mais de 21 homicídios qualificados consumados e outros 4 tentados.

Por fim, nota-se que tanto nos acórdãos de 1991/1992 quanto naqueles de $2001 / 2002$, é comum um argumento definitivo para a denegação da ordem: o fato de o réu já ter sido pronunciado ou sentenciado, sem que tenha havido trânsito em julgado.

\section{Análise De Resultados}

O confronto e a interpretação dos resultados quantitativos e qualitativos permitem extrair conclusões que não se limitam à definição do limite temporal que dá ensejo ao excesso de prazo. É possível chegar a cinco conclusões: (1) Não há marco temporal para separar o prazo razoável do excesso de prazo; (2) Em algumas ocasiões, o habeas corpus é utilizado como catalisador processual; (3) Tanto maior é a duração da prisão processual, quanto mais grave for a infração; (4) O conceito de complexidade do processo é incerto; (5) O comportamento da defesa é sobrevalorizado para justificar a mora jurisdicional.

\section{I NÃo há MARCo TEMPORAL PARA SEPARAR O PRAZO RAZOÁVEL do EXCESSO de PRAZO}

Ao contrário do que se supunha, ao se falar de prazo razoável e excesso de prazo, o lapso temporal não é fator preponderante na classificação da duração dos processos criminais. No biênio 2011/2012, a diferença da média de tempo em que a ordem foi concedida ou denegada em razão do excesso de prazo correspondeu a 16 dias (prazo razoável - 1229,40 dias; excesso de prazo - 1245,06 dias). Essa pequena variação temporal dá margem a que prisões processuais com 3 ou 4 anos de duração possam ser consideradas aceitáveis ou inaceitáveis dependendo de circunstâncias outras.

No período 2001/2002, houve reconhecimento do excesso de prazo quando a prisão provisória durava 1056,25 dias, mas a ordem foi negada quando o prazo equivalia a 750,5 dias. O divisor que separa o excesso do razoável foi mais perceptível porque a diferença entre eles se mostra superior a 300 dias. Contudo, por paradoxal que pareça, há inversão de valores no biênio 1991/1992. Considerou-se haver excesso de prazo para as prisões processuais com duração média de 435,67 dias, mas se entendeu razoável aguardar o julgamento preso por 748,5 dias. É certo que o pequeno número de acórdãos localizados no período pode ter contribuído para o resultado contraditório, em que o mais (prisão) significa menos (direito à liberdade) e o menos 
significa mais. Em tese, quanto maior for a duração da prisão, mais direito à liberdade haveria, porque mais próximo de se caracterizar o excesso de prazo. Isso talvez se explique em razão do tamanho da amostra, haja vista que, em pequenos conjuntos de dados, é possível achar associações aleatórias que não aparecem nos grandes conjuntos. Todavia, o resultado não destoa muito daquele encontrado no lapso temporal de 2011/2012, com maior número de acórdãos estudados, porque em ambos os períodos há demonstração de que a quantidade de tempo não mantém relação direta com o excesso ou a razoabilidade do prazo.

Nota-se que a caracterização do excesso de prazo demandou maior lapso temporal com o passar dos anos. Na década de 1990, eram suficientes 435,67 dias para configurar excesso de prazo. No biênio 2001/2002, considerou-se que a prisão processual com duração média de 1056,25 consistia em prazo excessivo. Por fim, no período mais recente, somente houve excesso de prazo na formação da culpa quando a prisão provisória alcançou, em média, 1245,06 dias. A maior tolerância com a morosidade processual também pode ser notada nos processos em que houve reconhecimento do trâmite regular das ações penais. Percebe-se a sequência crescente de 748,5 dias, 750,5 dias e 1229,40 dias nos períodos de 1991/1992, 2001/2002 e 2011/2012, respectivamente, referentes aos lapsos temporais tido como aceitáveis para manutenção da prisão provisória. Isso contraria as expectativas de celeridade da sociedade, porque a concepção de tempo no processo penal alargou-se nos últimos anos.

O HC 82.506/SP, de relatoria da Ministra Ellen Gracie, é uma exceção no conjunto de acórdãos pesquisados porque foi o único em que se utilizou elemento temporal objetivo para apuração do excesso de prazo: o desrespeito ao prazo de 50 dias previsto no art. 390 do CPPM culminou na concessão da ordem.

\subsection{UTILIZAÇÃO DO HabEAS CORPUS COMO CATALISAdOR PROCESSUAL}

$\mathrm{O}$ art. 648 do Código de Processo Penal estabelece as hipóteses em que há coação ilegal passível de ser sanada por meio do habeas corpus: quando não houver justa causa; quando alguém estiver preso por mais tempo do que determina a lei; quando quem ordenar a coação não tiver competência para fazê-lo; quando houver cessado o motivo que autorizou a coação; quando não for alguém admitido a prestar fiança, nos casos em que a lei a autoriza; quando o processo for manifestamente nulo; e quando extinta a punibilidade.

Em cada uma dessas situações, a ordem será concedida para trancamento da ação penal, reconhecimento de nulidade, extinção da punibilidade ou para conceder ou assegurar liberdade ao paciente. Sem embargo da relevante finalidade do habeas corpus, que poderia admitir ampliação das hipóteses de cabimento, não há expressa previsão para que funcione como catalisador processual, isto é, tenha o papel de acelerar o julgamento de ações penais. No mais recente biênio analisado, em que 33 habeas corpus foram deferidos, 14 deles tinham por objetivo determinar que a autoridade 
coatora julgasse a ação que deu ensejo à impetração. Posto que o STF sustentasse tratar-se de situação excepcional, ela se verificou em quase 50\% dos processos em que foi concedida a ordem. O tribunal procurou demonstrar estar agindo com cautela, para não interferir na pauta de julgamento de outros órgãos judiciais, mas essa preocupação reduziu o potencial de correção da ação constitucional. Nos biênios 1991/1992 e 2001/2002, não se notou o emprego dessa estratégia de catalisação processual e sempre que estava configurado o excesso de prazo o tribunal determinava a libertação do paciente. A recente interpretação enfraquece o papel do habeas corpus porque, ao mesmo tempo em que prorroga indevidamente a prisão processual, esvazia o encargo dos órgãos judiciais em velar por julgamento em prazo tolerável. O habeas corpus deixa de ser usado para alcançar a liberdade, baseado no fundamento de estar preso por mais tempo do que a lei determina, e é empregado como última chance para fazer cessar a ineficiência. A opção mostra-se arriscada porque nem sempre o julgamento pela instância inferior é feito em tempo hábil, o que contribui para prolongar o estado de prisão ilegal do paciente. O HC 109.349/MG é evidente exemplo do risco que se corre. Denegada a ordem em 25/10/11, sendo vencido o Ministro Celso de Mello, o STF expressamente determinou que o juiz de $1^{\circ}$ grau adotasse todas as providências necessárias para marcação da sessão do júri para julgamento do paciente. Foi preciso transcorrer o prazo de 1 ano e 10 meses (660 dias) após o julgamento do habeas corpus pela Corte Suprema, para que o réu preso fosse efetivamente julgado em primeira instância. ${ }^{2}$

Perde o acusado, que expia prisão por mais tempo do que determina a lei, nos dizeres do art. 648, II, do CPP; perde a sociedade, que fica privada de estímulos para que as instituições judiciárias funcionem com mais eficiência; perde o STF, que enfraquece, em vez de fortalecer, o remédio constitucional.

\subsection{TANTO MAIOR É A DURAÇÃO DA PRISÃo PROCESSUAL, QUANTO MAIS GRAVE FOR A INFRAÇÃO}

Constatou-se que a maior parte das infrações pelas quais respondiam os pacientes referia-se a delitos de severa gravidade. Parece truísmo afirmar, mas aqueles que permaneceram presos por maior lapso temporal respondiam pela suposta prática de crimes hediondos ou a eles equiparados, não raro, em concurso material.

Infrações mais graves, cuja gravidade se extrai da pena cominada ou de peculiaridades de sua execução, têm propensão a justificar o decreto de prisão preventiva e a segregação provisória por maior lapso temporal. Os crimes de homicídio doloso, por exemplo, uma vez que estão sujeitos ao procedimento bifásico do tribunal do júri, são julgados com menos rapidez. Logo, aguardar o processo em custódia significa permanecer preso por considerável lapso de tempo.

O mesmo raciocínio não deveria ser aplicado ao delito de tráfico ilícito de drogas, haja vista que o rito previsto na Lei n. 11.343/06 é concentrado e conta com fases 
que se sucedem em curtos intervalos. Todavia, a morosidade no trâmite processual, seja em primeira instância, seja nas fases recursais, parece ser imanente ao sistema de justiça brasileiro e é natural que a impugnação, em sucessivas instâncias, por meio do habeas corpus, ocorra com frequência.

A percepção da gravidade da infração, aliada à constatação preliminar da baixa relevância dos argumentos do impetrante, talvez expliquem por que motivo, nos casos em que se deu a denegação da ordem, apenas em duas ocasiões houve deferimento de medida liminar.

\subsection{O CONCEITO DE COMPLEXIDADE DO PROCESSO É INCERTO}

Se o reconhecimento do excesso de prazo não se baseia no aspecto temporal isoladamente, o tribunal vale-se de outros critérios para a construção do conceito. Como não existe, em regra, limite objetivo de duração dos processos de réu preso, a morosidade é realmente aferida pelo STF considerando-se as peculiaridades dos casos examinados. Como revelado, a quase totalidade dos julgados fez uso da expressão "complexidade do caso", conceito indeterminado cujo conteúdo é preenchido pelo julgamento de cada ação. O número de acusados superior a um consiste em opção decisiva para reputar a causa complexa, conquanto a complexidade não seja afastada quando a denúncia é oferecida contra um único agente.

Não há dúvida de que, quanto maior for o número de acusados, mais lenta tende a ser a evolução do processo. Contudo, o local da residência dos acusados, o fato de um deles estar foragido, se possuem defensores constituídos ou dativos e se são ou não facilmente localizados para citação e interrogatório podem ser preponderantes para avaliar a complexidade do processo.

O STF não despreza essas circunstâncias e, no conjunto de julgados, arrolou diversas causas da morosidade processual. A expedição de cartas precatórias, a quantidade de volumes do processo (sete no caso concreto), o número de acusados, a suspensão processual nos termos do art. 366 do CPP, a natureza dos crimes (mencionada em denúncias por tráfico ilícito de drogas), a existência de organização criminosa, o número de advogados, a tramitação de recursos e o número de crimes foram apontados como fatores que justificam o atraso na conclusão do processo. O art. 390, caput e $\S 1^{\circ}$, do Código de Processo Penal Militar (CPPM), é raro dispositivo que, além de estatuir limite temporal objetivo para conclusão dos processos criminais, prescreve a admissão de justificados acréscimos temporais. Segundo o dispositivo legal, "não será computada naqueles prazos a demora determinada por doença do acusado ou defensor, por questão prejudicial ou por outro motivo de força maior justificado pelo auditor, inclusive a inquirição de testemunhas por precatória ou a realização de exames periciais ou outras diligências necessárias à instrução criminal, dentro dos respectivos prazos". Nem todas as circunstâncias excludentes do excesso de prazo mencionadas pelo STF amoldam-se aos preceitos do CPPM. 
Percebe-se que a complexidade diagnosticada nos julgados provém exclusivamente das circunstâncias fáticas da tramitação processual e em nenhum momento é citada dificuldade na aplicação do direito material como causa de retardamento. Admite-se a existência de complexidade jurídica procedimental em razão de diversos fatores, conquanto não tenham sido mencionados entre eles a necessidade de provas periciais, conexão de ações, multiplicidade de incidentes processuais suscitados e a interação entre procedimentos administrativos e judiciais. Mas o surgimento de questões novas e de difícil interpretação, em face da maior densidade jurídica, nunca foi posto como justo motivo de desaceleração processual.

\subsection{O COMPORTAMENTO DA DEFESA É SOBREVALORIZADO PARA JUSTIFICAR A MORA JURISDICIONAL}

Esta última consideração é bastante controversa, pois se atribui à defesa culpa pela mora na conclusão do processo mesmo quando não lança mão de manobras visivelmente protelatórias. Por vezes, o simples exercício da ampla defesa, como, por exemplo, insistindo na oitiva de determinada testemunha ou requerendo a expedição de cartas precatórias, provoca a superação da alegação de excesso de prazo.

Se não há dúvida de que manobras protelatórias justificam o atraso, o uso excessivo de recursos não gera a mesma consequência, salvo se isso foi reconhecido pelas instâncias recursais (embargos de declaração protelatórios, questões incidentais manifestamente improcedentes, recursos incabíveis etc.).

Não basta que o Judiciário não tenha permanecido inerte, como decidido no HC 81.905/PE, para considerar refutada a alegação de excesso de prazo. Se a defesa não provocou o atraso, não deve o acusado suportar os ônus da demora jurisdicional. Assim como o réu não está obrigado a produzir provas que o incriminem, igualmente está dispensado de cooperar ativamente para acelerar o processo penal. A conduta dilatória do acusado deve ser identificada apenas quando faz uso capcioso dos meios que o ordenamento põe legitimamente à sua disposição. O uso voluntariamente distorcido do direito de defesa não se faz presente, por exemplo, na solicitação de oitiva de testemunhas por cartas precatórias, como decidido no HC 81.634/PR.

$\mathrm{O}$ acusado não pode ser penalizado por usar todos os recursos e meios de defesa previstos em lei. Se o Estado oferece vasta gama de recursos e meios de impugnação, não pode coibir o defensor de fazer amplo uso deles, tal como reconhecido no HC 81.149/RJ, em que foi concedida a ordem porque a defesa não pode suportar a demora por ter a sentença de pronúncia sido anulada três vezes.

Por fim, o STF firmou entendimento de que incumbe ao acusado demonstrar que o atraso na conclusão do processo não pode ser imputado a ele. Embora o ônus da prova no processo penal fique a cargo da acusação, no específico caso do habeas corpus, atribuiu-se a incumbência de provar ao autor da ação constitucional, a exemplo do que acontece ordinariamente no processo civil. Como não foi possível, no HC 
$81.780 / \mathrm{RJ}$, identificar se o excesso de prazo decorria de culpa da defesa ou do Judiciário, denegou-se a ordem.

\section{ConClusÃo}

O excesso de prazo na formação da culpa é o reverso da moeda do prazo razoável. O primeiro associa-se ao atraso na prestação jurisdicional, cujo conceito parece evidente e definido: todo lapso de tempo além do necessário para julgar determinado processo. O segundo importa em conduzir os processos em tempo tolerável. Num país em que não se prima por ser reconhecido como fornecedor de prestação jurisdicional eficiente, conseguir a razoável duração do processo merece comemoração.

O STF faz o controle da temporalidade dos processos criminais em que há réus presos, por meio de habeas corpus. A diferença em relação ao TEDH reside no fato de que a corte nacional infere o conceito de razoável duração para limitar a extensão da prisão provisória, ao passo que o tribunal europeu avalia o excesso de prazo para fins de fixação de indenização patrimonial.

A principal conclusão da pesquisa contrapõe-se à comum percepção de que o tempo é fator decisivo na análise do que seria aceitável ou inaceitável em termos de duração do processo. Se o lapso temporal transcorrido não é traço distintivo entre prazo razoável e excesso de prazo, por outro lado não desempenha papel mínimo ou desprezível na aferição do aceitável e inaceitável, senão que deve ser avaliado em conjunto com outros fatores. A exemplo da concepção do tempo como instituição social, defendida por Ost, a Corte Suprema parece abandonar o curso do tempo físico e opta por temporalizar o conceito de razoável duração e excesso de prazo com base na complexidade do processo e na gravidade da infração, que, por vezes, possuem mais peso para justificar a manutenção da prisão processual.

A princípio, duas opções teria o STF para distinguir prazo razoável de excesso de prazo: limites temporais objetivos ou análise casuística. O indeterminado conceito de "complexidade do processo", adotado pelo tribunal e elaborado caso a caso, contrapõe-se a marcos temporais que evitariam incerteza. Apresenta aspecto positivo por sopesar muitas circunstâncias em cada processo examinado, de forma a extrair decisão que se amolde às particularidades da situação jurídica de cada acusado. O ponto negativo situa-se nas incoerências que podem ser geradas, em que o tempo deixa de ser fator crucial na medição do excesso de tempo, e na possibilidade constatada de o prazo do excesso ser inferior ou equivalente ao lapso de tempo do razoável.

Por fim, todos os atores processuais devem ter as condutas avaliadas para detectar se contribuíram para a mora do julgamento final. O comportamento da defesa não pode ser sobrevalorizado para justificar a mora jurisdicional, nem legítimas manifestações processuais, realizadas com amparo legal, serem tidas como diligências 
protelatórias. A conduta dilatória do acusado deve ser identificada apenas quando faz uso capcioso dos meios que o ordenamento põe legitimamente à sua disposição.

\section{NOTAS}

1 BRASÍLIA. Supremo Tribunal Federal. Relator Ministro Gilmar Mendes, Segunda Turma, HC 109.349/MG, Julgado em 25/10/11, DJe de 6/3/12.

2 JÚRI CONDENA TRÊS A MAIS DE 220 ANOS DE PRISÃO PELA CHACINA DE UNAÍ. G1. 31 ago. 2013. Disponível em: <http://g1.globo.com/minas-gerais/noticia/2013/08/juri-condena-tres-por-chacina-em-unai.html>. Acesso em: 26 mar. 2014

\section{REFERÊNCIAS BIBLIOGRÁFICAS}

BADARÓ, Gustavo Henrique Righi. LOPES JÚNIOR, Aury. Direito ao processo penal no prazo razoável. Rio de Janeiro, Lumen Juris, 2006.

BRACARENSE, Paulo Afonso. Estatística aplicada às ciências sociais. Curitiba: IESDE Brasil S/A, 2012.

FARIA, José Eduardo. O direito num cenário em transformação. Revista Brasileira de Ciências Criminais, São Paulo, n. 17, jan./mar., 1997.

KOEHLER, Frederico Augusto Leopoldino. A razoável duração do processo. $2^{\text {a }}$ ed. Bahia: Juspodium, 2013.

OST, François. El tiempo del derecho. Buenos Aires: Siglo XXI, 2005.

RANGEL, Paulo. Direito processual penal. 20ª ed. São Paulo: Atlas, 2012.

SANTOS, Boaventura de Sousa et alli. Para um novo judiciário: qualidade e eficiência na gestão dos processos cíveis. Coimbra: Observatório Permanente da Justiça Portuguesa, 2008.

STEELMAN, David C. Improving caseflow management: a brief guide. Williamsburg: National Center for State Courts, 2008. 
$\mathbf{6 5 4}$ : DOIS LADOS DA MESMA MOEDA: O TEMPO NO STF

\title{
Lucas Bacelette Otto Quaresma
}

Ibquaresmaldgmail.com

\author{
Bacharel em Direito PELA UFMG \\ AsSESSOR Jurídico da Procuradoria da \\ República em Minas Gerais
}

